\title{
Prp21, a U2-snRNP-associated protein, and Prp24, a U6-snRNP-associated protein, functionally interact during spliceosome assembly in yeast
}

\author{
VAIJAYANTI C. VAIDYA and USHA VIJAYRAGHAVAN* \\ Department of Microbiology and Cell Biology, Indian Institute of Science, Bangalore 560012, India
}

\begin{abstract}
Earlier studies on genetic suppression of prp24-1 by prp21-2 suggested an association between yeast Prp21 and Prp24 proteins, which are associated, respectively, with U2 snRNA and U6 snRNA. Here we report analyses of physical and functional interaction between these factors. Missense mutations in functionally important domains reside in prp21-2 and prp24-1. Two-hybrid assays do not detect interaction between wild-type or mutant proteins. Prp21-2 and Prp24-1 protein in prp21-2 or prp24-I extracts can be heat-inactivated in vitro. In contrast, heat-treated extracts from the revertant strain prp21-2 prp24-1 demonstrate allele-specific restoration of splicing. Suppression of prp24-1 by prp21-2 does not cause coimmunoprecipitation of $\mathrm{U} 2$ and U6 snRNAs. We demonstrate the presence of $\operatorname{Prp} 21$ in the spliceosome assembly intermediate A2-1, and our data suggest the presence of Prp24 in the same complex. Kinetic analysis of assembly in heattreated revertant extracts reveal a rate-limiting conversion of complex B to A2-1, suggesting transient association between the mutant proteins at this step. Our data also imply a requirement for Prp21 during B to A2-1 conversion. We conclude that a transient yet likely functional association between Prp21 and Prp24 occurs during spliceosome assembly.
\end{abstract}

[Vaidya V. C. And Vijayraghavan U. 1998 Prp21, a U2-snRNP-associated protein, and Prp24, a U6-snRNP-associated protein, functionally interact during spliceosome assembly in yeast. J. Genet. 77, 85-94]

\section{Introduction}

Intron excision from nuclear pre-mRNA by two transesterification reactions requires assembly of a ribonucleoprotein complex, the spliceosome, from five small nuclear ribonucleoprotein particles (snRNPs), namely U1, U2, U5 and U4/U6, and several protein factors. The catalytic core of the spliceosome is thought to be comprised of RNA components, with proteins functioning to facilitate its formation (Guthrie 1991; Moore et al. 1993). A large number of the proteins (snRNP and non-snRNP) required for pre-mRNA splicing have been identified by genetic screens in yeast. Biochemical and molecular analyses have identified specific roles for some of these proteins (Vijayraghavan and Abelson 1989; Vijayraghavan et al. 1989; Ruby and Abelson 1991; Beggs 1993).

*For correspondence. E-mail: uvr@mcbl.iisc.ernet.in.
Assembly and activation of the spliceosome requires conformational changes in several RNA-RNA and RNAprotein complexes (Madhani and Guthrie 1994; Kim and Lin 1996; Xu et al. 1996), and one well-documented rearrangement involves U6 snRNA. U6 snRNA enters the spliceosome as U4/U6/U5 tri-snRNP complex wherein it is extensively base-paired with U4 snRNA (Cheng and Abelson 1987; Brow and Guthrie 1988). Assembly of the U4/U6 snRNP particle occurs prior to tri-snRNP formation and requires protein factors (Shannon and Guthrie 1991; Raghunathan and Guthrie 1998). Coalescence of U4/U6/U5 tri-snRNP with the prespliceosome complex $B$, which contains $\mathrm{U} 1$ and $\mathrm{U} 2$, results in the A2-1 complex containing all five U snRNPs. However, disassembly of U4/U6 snRNP and release of $\mathrm{U} 4$ snRNA from the A2-1 complex are essential prior to the first step of the splicing reaction (Cheng and Abelson 1987; Yean and Lin 1991). Coincident with the dissociation of U4/U6 hybrid, a mutually exclusive U2-U6 snRNA interaction occurs that is essential for

Keywords. yeast; pre-mRNA splicing; PRP21; PRP24; protein interactions. 
catalytic activation. In addition, U6 snRNA replaces the U1 snRNA in base-pairing interaction with the $5^{\prime}$ splice site of the substrate (Madhani and Guthrie 1994). The structural rearrangements displayed by U6 snRNA thus have a central role, and the role of protein factors in mediating these conformational changes is therefore of interest.

Prp24 is a factor involved in these rearrangements. The earliest clue to its role as an essential factor was obtained from the finding that the temperature-sensitive (ts) prp24-1 mutant has defects before the first chemical step of splicing (Vijayraghavan et al. 1989). Subsequent studies of mutants in PRP24 revealed a role in the annealing of $\mathrm{U} 4$ and $\mathrm{U} 6$ snRNAs (Shannon and Guthrie 1991; Jandrositz and Guthrie 1995). These functions are consistent with Prp24 having three RNA recognition motifs (RRMs) found in other suRNP proteins (Scherly et al. 1990; Birney et al. 1993; Tang et al. 1996). Immunoprecipitation and in vitro studies confirm that Prp24 binds U6 snRNA and promotes annealing of U4 and U6 snRNAs or snRNPs (Shannon and Guthrie 1991; Ghetti et al. 1995; Raghunathan and Guthrie 1998). Suggestions that Prp24 is a part of the spliceosome, where it possibly facilitates dissolution of $\mathrm{U} 4 / \mathrm{U} 6$ hybrid, come from the finding that Prp24 binds preferentially to partially unwound stem II of this hybrid RNA (Ghetti et al. 1995). Thus a dual role is predicted for $\operatorname{Prp} 24$ : one for the formation of the U4/U6 particle before U4/U5/U6 joins the spliceosome and the other at or during the exit of U4 snRNA from the spliceosome.

To identify factors that interact with $\operatorname{Prp} 24$, we had previously used a genetic screen for second-site suppressors of ts prp24-1. A mutually allele-specific interaction between prp24-1 and prp21-2 was defined (Vaidya et al. 1996). Suppression did not occur by a bypass pathway, and suppression by prp 21-2 was dominant, implying a gain of function. These genetic properties are consistent with a physical interaction between the proteins resulting in functional compensation, or with a functional interaction without direct contact. Prp21 is a U2-snRNP-associated factor which, together with Prp9, Prp11 and Prp5, recruits U2 to form the complex B (Arenas and Abelson 1993; Legrain et al. 1993; Ruby et al. 1993; Wiest et al. 1996). Thus Prp21 functions are required prior to addition of U4/U5/U6 tri-snRNP during spliceosome assembly. In the study reported here, we employed in vivo and in vitro approaches to investigate physical and functional association between $\operatorname{Prp} 21$ and Prp24. Our data suggest an interaction during conversion of complex B to A2-1, and thus the presence of both proteins in splicing complexes.

\section{Materials and methods}

Plasmid constructs and yeast strains: The PRP2I open reading frame (ORF) was amplified from $P R P 21 \mathrm{pBS}$ (Arenas and Abelson 1993), with oligo21.1 positioned at the start of the ORF and the M13 reverse primer, to introduce EcoRI and $X h o I$ sites respectively. The product was cloned at compatible sites of the Gal4 DNA binding domain (DB) vector pGBT9 (Fields and Song 1989; Chien et al. 1991) to generate Gal4DB-PRP21, which was sequenced. The PRP24 ORF in PRP24pBS (contains a 3.8-kb Xbal genomic fragment; provided by J. Abelson, Caltech, USA) was amplified with oligos 24.1 and 24.2 to introduce a BamHI site $5^{\prime}$ to the start codon and a Sall site at the predicted $3^{\prime}$ transcription termination site. The $1.3-\mathrm{kb}$ PCR product was cloned in the Gal4 activation domain (AD) vector pGAD424 (Fields and Song 1989; Chien et al. 1991) to generate Gal4AD-PRP24. The entire ORF was sequenced and also subcloned into pGBT9 at the BamHI and Sall sites to generate Gal4DB-PRP24.

The yeast strains used, prp21-2, prp24-1, prp21-2 prp241, prp21-1 prp24-1, prp21-1 and SS330, have been described previously (Vaidya et al. 1996). The yeast strain Hf7c (MATa ura3-52 leu2-1 trpl ade2-101 his3 200 pGAL1 HIS3, pGAL1 LacZ) was used in two-hybrid assays.

\section{Mutations in prp24-1 and prp21-2; their cloning into two-hybrid} vectors: The 1.3-kb prp24-1 ORF was amplified with oligo 24.1 and oligo 24.2 and genomic DNA from prp24-1 and was cloned in pBS to give prp24-IpBS. The complete sequence in each of two independent recombinants was determined. The genomic prp2l-2 locus was cloned by plasmid rescue (Seshadri and Vijayraghavan 1995) and used in sequence analysis. Subsequently, the plasmid prp 21 2pRS305 was the template for PCR with oligos 21.1 and T3; the resulting amplified prp21-2 ORF (900 bp) was digested with EcoRI and XhoI and cloned into pGBT9. prp21-2 was also similarly cloned in pGAD424. The prp241 ORF from prp24-1pBS was subcloned as a BarnHI and SalI fragment into pGBT9 and pGAD424. The recombinants were sequenced to obviate cloning artifacts.

The sequences of the oligonucleotides used:

\section{Oligo 24.1 5' CTTCATAATGGATCCTAATGGAG Oligo 24.2 5' GTTAGTCGACTCACCTAGAAAGAT Oligo 21.1 5' AGTTGAATTCATGGAACC Oligo T3 5' AATTAACCCTCACTAAAGGG.}

Two-hybrid assay: Yeast transformants were selected on minimal media lacking leucine and tryptophan for the two plasmids, one in pGBT9 and the other in pGAD424 vector backgrounds. Single colonies bearing the following combinations of plasmids were tested for interactions: PRP21pGBT9 and PRP24pGAD424, PRP24pGBT9 and PRP2lpGAD424, prp24-1pGBT9 and prp21-2pGAD424, prp24-1pGBT9 and PRP21pGAD424, prp21-2pGBT9 and PRP24pGAD424, $P R P 24$ pGBT9 and prp21-2pGAD424. Blue coloration on galactose minimal media lacking leucine and tryptophan but containing X-gal (1.6 mg per plate) was taken to imply interaction; as was growth on galactose minimal media lacking leucine, tryptophan and histidine.

In vitro splicing assays: Preparation of splicing extracts and standard splicing reactions were done as previously reported 
(Lin et al. 1985). Heat inactivation of the mutant proteins was done by incubation of the extracts at $39^{\circ} \mathrm{C}$ for $7 \mathrm{~min}$ prior to use in assays. Spliceosomal complexes were analysed by electrophoresis through native $3 \%$ polyacrylamide gels (20:1 acrylamide:bisacrylamide) in $1 \times \mathrm{TAE}$ ( $40 \mathrm{mM}$ Tris-acetate, $1 \mathrm{mM}$ EDTA, pH 7.2 , at $20^{\circ} \mathrm{C}$ ). For synthesis of very-high-specific-activity pre-mRNA, run-off transcription reactions contained no unlabelled UTP and instead had 100 to $150 \mu \mathrm{Ci}\left[\alpha-{ }^{32} \mathrm{P}\right] \mathrm{UTP}(3000 \mathrm{Ci} / \mathrm{mM})$. Unlabelled actin pre-mRNA was synthesized from $5 \mu \mathrm{g}$ template with $3 \mathrm{mM}$ of each $\mathrm{NNTP}$. All in vitro synthesized substrates were purified from the gel.

snRNA immunoprecipitation and immunodepletion of splicing complexes: Antibody binding to Protein-A-Sepharose 6MB beads was done as described previously (Arenas and Abelson 1993). To immunoprecipitate U snRNAs from extracts, $10 \mu \mathrm{l}$ of the specified extract was mixed with $10 \mu \mathrm{l}$ of the specified immobilized antiserum. The bead-bound snRNAs were extracted, and analysed on Northern blots by probing simultaneously for all spliceosomal $U$ snRNAs (Arenas and Abelson 1993). For immunoprecipitation of snRNAs from splicing reactions, unlabelled actin premRNA (25 fmol) and $12.5 \mu \mathrm{l}$ of the specified extract were used in $25-\mu \mathrm{l}$ reactions. After $10 \mathrm{~min}$ at $23^{\circ} \mathrm{C}$, an aliquot of each reaction was added to $10 \mu \mathrm{l}$ of a specific immobilized antiserum and then processed. Immunodepletion of splicing complexes and analysis of the substrate RNA species in the bound complexes were done as described previously (Arenas and Abelson 1993; Wiest et al. 1996), except that the reactions contained $60 \mu \mathrm{M}$ ATP. The anti-Prp21 antiserum used was that described previously (Arenas and Abelson 1993), and the anti-Prp24 antiserum was kindly provided by J. Abelson, Caltech, USA.

Inactivation of Prp21-2 in $B$ and A2-1 complexes: prp21-2 extracts were used in reactions with $3 \mathrm{mM}$ ATP or $60 \mu \mathrm{M}$ ATP. A $16-\mu$ l extract was used in a $40-\mu l$ reaction with $60 \mu \mathrm{M}$ ATP, incubated at $23^{\circ} \mathrm{C}$ for $30 \mathrm{~min}$. A $10-\mu 1$ aliquot of the reaction mix was stopped on ice with the addition of $0.2 \mu \mathrm{l}$ of heparin $(20 \mathrm{mg} / \mathrm{ml})$. The remainder of the reaction was used as follows. Aliquot $1,10 \mu \mathrm{l}$, was supplemented with ATP to $3 \mathrm{mM}$ and incubated at $23^{\circ} \mathrm{C}$ for $30 \mathrm{~min}$; the reaction was then stopped on ice. Aliquot 2, of $20 \mu 1$, was heated at $39^{\circ} \mathrm{C}$ for $7 \mathrm{~min}$ to inactivate $\operatorname{Prp} 21-2$, and $10 \mu \mathrm{l}$ of this sample was transferred to ice immediately; to the remaining $10 \mu 1$ of heat-treated complexes, ATP was added to $3 \mathrm{mM}$, and the reaction continued for $30 \mathrm{~min}$ at $23^{\circ} \mathrm{C}$ and then stopped on ice. From each of these reactions, 5- $\mu$ l samples were analysed for complexes; the substrate and product RNAs in the remaining $5 \mu$ were also analysed.

To assess complete inactivation of Prp21-2 protein in A21 complex, the following assays were done. A 40- $\mu 1$ reaction with unlabelled actin pre-mRNA (50 fmol) and $20 \mu$ l of prp $2 I-2$ extract was incubated in buffer containing $60 \mu \mathrm{M}$ ATP. After $30 \mathrm{~min}$ at $23^{\circ} \mathrm{C}$, one aliquot of $9 \mu \mathrm{l}$ was supplemented with ATP to $3 \mathrm{mM}$ and $1 \mu \mathrm{l}$ of a second substrate (radiolabelled high-specific-activity pre-mRNA, $120,000 \mathrm{cpm} / \mu \mathrm{l}$ ) and then incubated for $30 \mathrm{~min}$ at $23^{\circ} \mathrm{C}$. A second aliquot of $18 \mu \mathrm{l}$ was heat-treated at $39^{\circ} \mathrm{C}$ for $7 \mathrm{~min}$, supplemented with ATP and $1 \mu \mathrm{l}$ of the second, radiolabelled substrate; a $10-\mu l$ aliquot of this sample was immediately put on ice and the remaining $10 \mu$ incubated at $23^{\circ} \mathrm{C}$ for $30 \mathrm{~min}$. The radiolabelled complexes and substrate and product RNA in these experiments were analysed.

\section{Results}

\section{Mutations in prp24-1 and prp21-2 are in functionally important domains}

To facilitate assessment of interaction between prp21-2 and prp24-1, we cloned and characterized these chromosomal mutant alleles. Sequence analysis of prp21-2, after rescue on a plasmid, defined a $G$ to $A$ mutation that changes cysteine 164 to tyrosine (table 1 ). Sequence characterization of prp24-1 showed that the ts phenotype possibly results from two mutations, both $\mathrm{A}$ to $\mathrm{G}$ transitions, which change lysine 46 to arginine and lysine 191 to glutamic acid (table 1). Thus mutations in prp24-I map to the RRM domains, which are functionally important for U6 snRNA stability (Vaidya et al. 1996) and consequently for splicing.

We employed the two-hybrid assay (Fields and Song 1989; Chien et al. 1991) to examine in vivo association between $\operatorname{Prp} 21$ and Prp24 (wild-type or mutant proteins). The wild-type $P R P 21$ and $P R P 24$ open reading frames (ORF) were expressed as fusions with Gal4 DNA binding domain (Gal4DB) or Gal4 transcription activation domain (Gal4AD). We determined by in vivo complementation that the Gal4DB-Prp21 fusion protein was functional, but found, however, that PRP24 fusions to Gal4DB or Gal4AD

Table 1. Mutations in alleles of prp24 and prp21.

\begin{tabular}{lcccc}
\hline Allele & Position & Amino acid change & Sequence feature & Reference \\
\hline ts prp24-1 & 46 & K to R & RRM1; RNP2 & This study \\
& 191 & K to E & RRM2 & Shannon and Guthrie (1991) \\
prp24-2 & 250 & C to R & RRM3; RNP1 & Shannon and Guthrie (1991) \\
prp24-3 & 248 & N to S & RRM3; RNP1 & Shannon and Guthrie (1991) \\
ts prp24-4 & 212 & L to P & RRM3; RNP2 & This study \\
ts prp21-2 & 164 & C to Y & & Chapon and Legrain (1992) \\
spp91-1 & 168 & T to A & & \\
\hline
\end{tabular}


did not result in complementation of prp24-1 (data not shown). Translational fusions between prp21-2 and Ga14DB or Gal4AD, and a fusion of prp24-1 to Gal4AD were generated (see Materials and methods). For the trans-activation assay, pairwise combinations of Gal4DB and Gal4AD fusion constructs were expressed in the yeast strain $\mathrm{Hf} 7 \mathrm{c}$, where interactions between any two fusion proteins result in histidine prototrophy and expression of $\beta$-galactosidase. We found that the various combinations of the wild-type proteins, or combinations of a mutant protein with a wildtype protein, or combination of the two mutant proteins Prp21-2 and Prp24-1 did not interact within the limits of this assay (data not shown). The absence of an apparent interaction between Prp21 and Prp24 proteins implies lack of a stable association. We then tested the possibility of spliceosome-dependent transient association.

\section{In vitro splicing assays demonstrate biochemical suppression} between prp24-I and prp21-2 alleles

To probe the biochemical basis of interaction, we tested whether suppression occurs in vitro. Splicing extracts from several strains-prp21-1, revertant prp21-2 prp24-1, prp211 prp24-1, prp21-2, and wild type-were analysed for in vitro splicing. Heat treatment of extracts from wild-type cells did not affect the efficiency of splicing (figure 1, lane 2). Complete irreversible inactivation of the mutant Prp21 protein occurred when extracts from prp21-2 or prp21-1 were heat-treated (figure 1, lanes 8 and 10). The in vitro splicing-defective phenotype of prp21-2 is consistent with the in vivo accumulation of pre-mRNA at the nonpermissive temperature (Vaidya et al. 1996). We tested specifically whether the conditions that inactivate Prp21-2 could inactivate Prp24-1. Extracts from prp24-1 cells spliced efficiently at $23^{\circ} \mathrm{C}$ but lost activity completely on heat treatment (figure 1, lanes 5 and 6). Under conditions of heat treatment that inactivated both Prp21-2 and Prp24-1, extracts from the revertant strain (double mutant) spliced efficiently (figure 1, lane 4). Therefore a complete suppression of the individual splicing phenotypes of prp21-2 and prp24-1 occurs in vitro. This property is allele-specific since extracts from the strain prp21-1 prp24-1 are not heat-resistant (figure 1, lane 12 versus lane 4). Having demonstrated in vitro suppression between prp24-1 and prp21-2, we investigated its biochemical basis and the requirement of Prp21 during spliceosome assembly.

In strain prp21-2 prp24-1, immunoprecipitation of $U 2$ by antiPrp21 antiserum and of 46 by anti-Prp24 antiserum is restored

Prp21, and its mammalian homologue SF3a 120 or SAP114, have been detected in the prespliceosome complex $B$ and in more mature complexes (Gozani et al. 1994; Wiest et al. 1996). Although presence of Prp24 in splicing complexes is inferred, no conclusive evidence exists. Immunoprecipitations of U snRNAs from cell-free extracts or splicing complexes by anti-Prp 24 or anti-Prp21 serum were done to

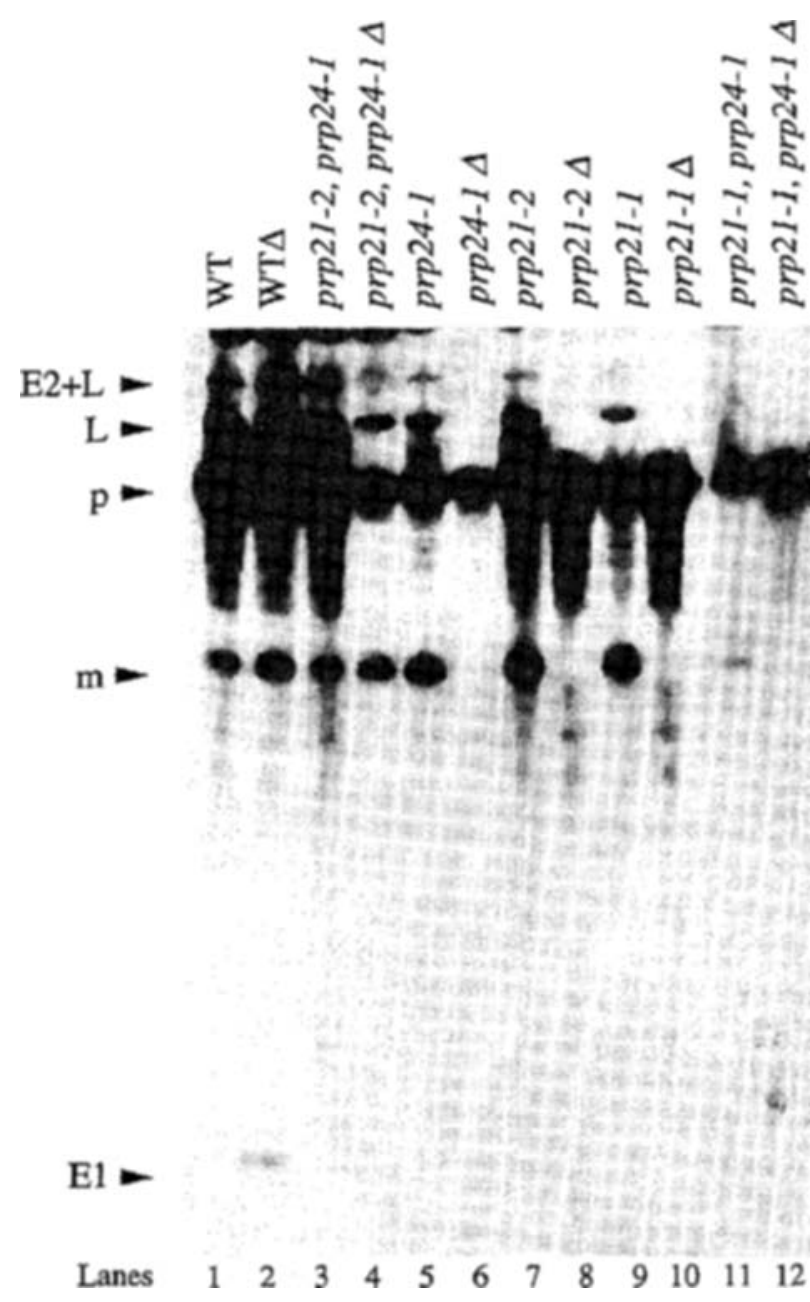

Figure 1. In vitro inactivation and suppression of Prp24-1. The indicated splicing extracts were assayed under standard conditions (lanes $1,3,5,7,9,11$ ). For inactivation of mutant proteins, the extracts were heat-treated at $39^{\circ} \mathrm{C}$ for $7 \mathrm{~min}(\Delta)$ prior to the assay (lanes $2,4,6,8,10,12$ ). The RNA species were analysed by denaturing PAGE. p, Pre-mRNA; E2+L, lariat intermediate; E1, exonl; m, mRNA; L, lariat intron.

examine protein-protein interactions. Coimmunoprecipitation of $\mathrm{U} 2$ and $\mathrm{U} 6$ snRNAs from extracts would indicate interaction in the free pool of snRNPs, while that from splicing reactions would imply interaction during spliceosome assembly. We studied interactions in extracts from the revertant strain, and used wild-type extracts and single-mutant extracts as controls. Anti-Prp21 antiserum precipitated U2 snRNA from prp21-2 prp24-1, prp21-1 prp24-1, prp21-2, prp24-1 and prp21-1 extracts (figure $2 \mathrm{~A}$, lanes $4,7,10,13$ and 16). Heat treatment of extract abolished U2 snRNA precipitation from $p r p 21-1$ and $p r p 21-2$ extracts (figure 2A, lanes 17 and 11 respectively). In contrast, such treatment failed to affect precipitation of U2 snRNA from wild-type and revertant extracts (figure 2A, lanes 2 and 5). Heat treatment per se does not affect availability of Prp21 epitopes, since U2 snRNA is immunoprecipitated from heat-inactivated prp24-1 extracts (figure $2 \mathrm{~A}$, lane 14). The lack of 


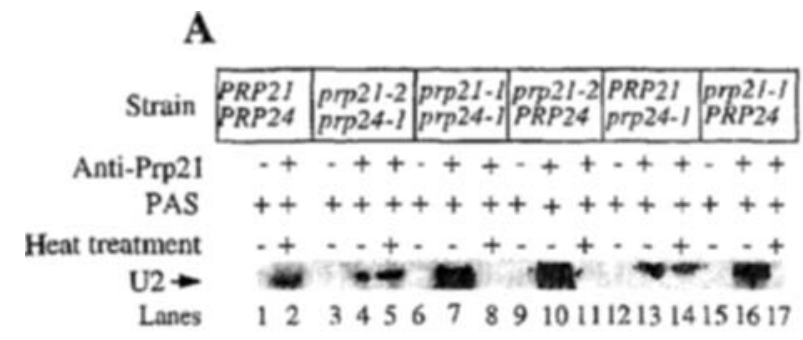

B

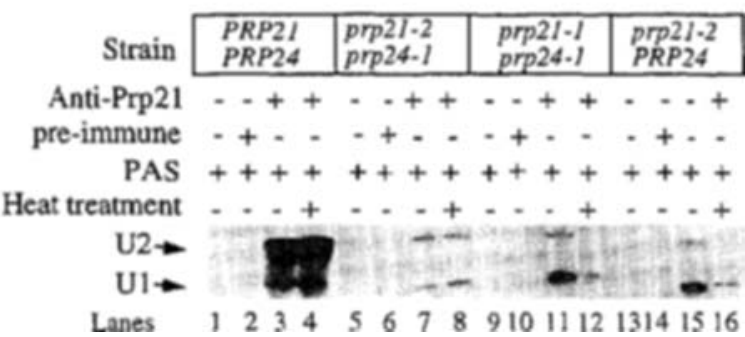

Figure 2. Precipitation of snRNAs with anti-Pıp21 antiserum. (A) Extracts from the strains indicated were taken for immunoprecipitation prior to $(-)$ or after $(+)$ heat treatment. Incubation was with either Protein-A-Sepharose beads without antibody (PAS) or with immobilized anti-Prp21. (B) The indicated extracts prior to $(-)$ or after $(+)$ heat treatment were used in splicing reactions with unlabelled pre-mRNA. The complexes in an aliquot of these reactions were bound to PAS beads, immobilized preimmune serum, or immobilized anti-Prp21 antiserum. In both $A$ and $B$, immunoprecipitated snRNAs were extracted, electrophoresed, and detected by Northern blotting and probing with U1, U2, U4, U5 and U6 snRNA gene probes simultaneously. The suRNA species detected are shown.

association between inactive $\operatorname{Prp} 21-1$ protein and U2 snRNA is consistent with the block in B complex formation after heat treatment (Arenas and Abelson 1993). While suppression of the inability of heat-inactivated Prp21-2 to precipitate U2 snRNA was observed in extracts from the revertant strain, coprecipitation of other $U$ snRNAs was not observed. Splicing complexes assembled with unlabelled substrate precipitated only $\mathrm{U} 2$ in immunoprecipitation with anti-Prp21. No U6 snRNA was observed even from revertant extracts (figure 2B, lane 8). Precipitation of U1 snRNA by this antiserum is known to occur even at $0.2 \mathrm{M} \mathrm{KCl}$ (Arenas and Abelson 1993), and is consistent with the presence of $\operatorname{Prp} 21$ in prespliceosomes, which contain both U1 and U2 snRNAs. In addition our data hint at the possibility that inactivated mutant Prp21-1 or Prp21-2 associate with U1 snRNA, possibly that present in commitment complexes, as U1 precipitation is consistently observed under these conditions where prespliceosomes do not form (figure $2 \mathrm{~B}$, lanes 12 and 16 ).

Anti-Prp24 antiserum precipitated only U6 snRNA from the following extracts: wild type, revertant, prp21-1 prp24-1 and prp24- $I$ (figure $3 \mathrm{~A}$, lanes 2, 5, 8 and 11). The precipitation profile remained the same even from splicing reactions with these extracts (figure 3B). No U6 snRNA was preci-

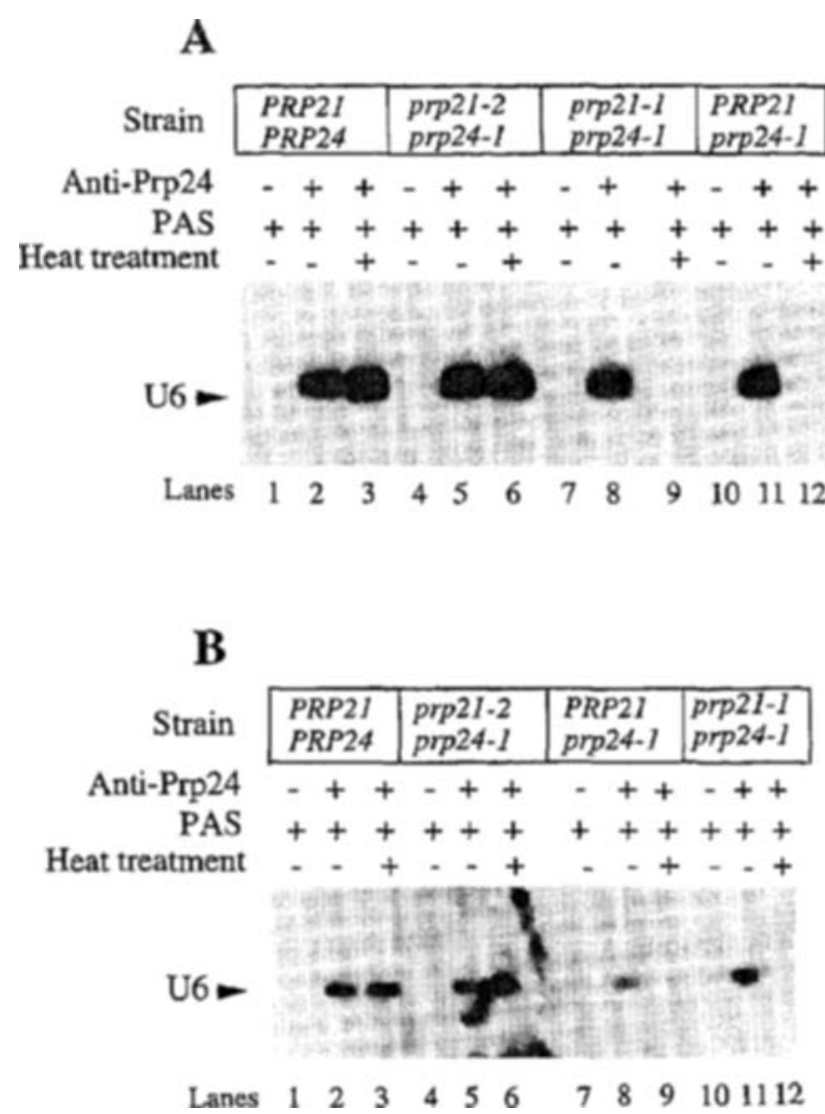

Figure 3. Precipitation of snRNAs with anti-Prp24 antiserum. (A) snRNAs were immunoprecipitated from indicated extracts either prior to $(-)$ or after $(+)$ heat treatment by addition to either Protein-A-Sepharose without antibody (PAS), or with immobilized anti-Prp24. (B) snRNAs immunoprecipitated and detected in aliquots of splicing reactions constituted as described in figure 2 Detection of the precipitated snRNAs was by Northern blotting and probing with all five spliceosomal snRNA gene probes. Only U6 was detected and that portion of the blot is shown.

pitated from the heat-treated prp 24- 1 extracts (figure $3 \mathrm{~A}$, lane 12), whereas U6 snRNA was precipitated from wild-type and prp21-2 prp24-1 extracts even after heat treatment (figure $3 \mathrm{~A}$, lanes 3 and 6 respectively). These data are consistent with the increased in vivo stability of U6 snRNA in the revertant strain (Vaidya et al. 1996). In summary, the inability to precipitate $\mathrm{U} 2$ with anti-Prp21 or U6 with anti-Prp24 in extracts from prp 21-2 or prp 24-1 is suppressed in the doubly mutant revertant prp24-1 prp21-2 in an allele-specific manner (in figure $2 \mathrm{~A}$ compare lanes 5 and 8 , and in figure $3 \mathrm{~A}$ compare lanes 6 and 9). However, coimmunoprecipitation of U2 and U6 snRNAs was not observed. Therefore, while we did not detect a stable interaction between Prp21 and Prp24 by this analysis, the likelihood of a transient interaction during spliceosome assembly cannot be ruled out.

\section{A2-1 complex contains Prp21 and possibly Prp24}

Spliceosomal complexes have been defined on the basis of their snRNA components and their ordered appearance 
A

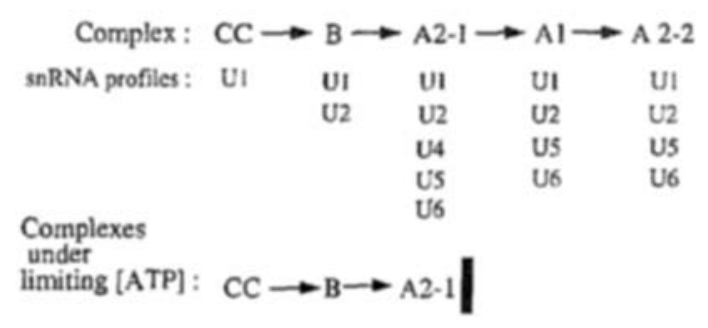

B

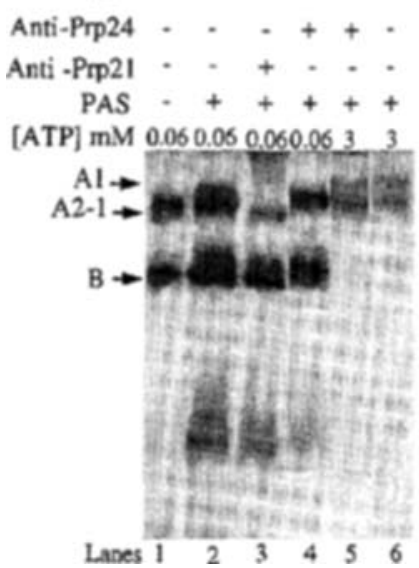

C

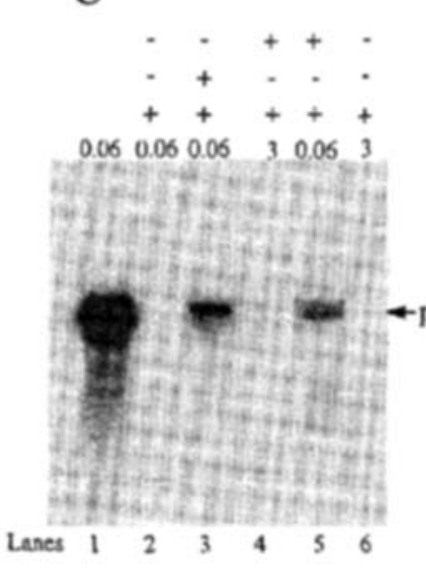

Figure 4. Assays to detect Prp21 and Prp24 in spliceosomal complexes. (A) Pathway of assembly of the active spliceosome, with the snRNA contents of each complex. The complexes accumulated in reactions with limiting ATP are also depicted. CC, Commitment complex; B, prespliceosome; A2-1, intermediate complex; A1, spliceosome; A2-2, catalytically active spliceosome. (B) Extracts from wild-type strain SS330 were used in splicing reactions (with the indicated amount of ATP) and incubated at $23^{\circ} \mathrm{C}$ for $10 \mathrm{~min}$. The extracts were taken for immunoprecipitation with preimmune serum bound to Protein-A-Sepharose (PAS), inmobilized anti-Prp21 antiserum, or immobilized anti-Prp24 antiserum. Unbound complexes were visualized by autoradiography after separation on native PAGE. Complexes of mobility greater than complex B are nonspecific complexes in this gel system. (C) The immunoprecipitated complexes were deproteinized, and the RNA substrate and products were visualized by autoradiography after separation on denaturing PAGE; $p$ denotes pre-mRNA. Note that the lane numbers in panel $\mathrm{C}$ do not coincide with those in $B$. Lane 1 in panels $B$ and $C$ are control reactions not subjected to imnunoprecipitation.

(figure 4A). However, association of many Prp proteins with these complexes is not yet clear. Since A2-1 intermediate is the first complex that contains both $\mathrm{U} 2$ and U6 snRNAs, we assessed whether $\operatorname{Prp} 21$ and $\operatorname{Prp} 24$ proteins coexist in this complex. A2-1 is a transient intermediate, hence we selectively accumulated A2-1 and B complexes by limiting ATP in the reaction to $60 \mu \mathrm{M}$ (figure $4 \mathrm{~A}$ ). Standard splicing reactions contain $3 \mathrm{mM}$ ATP and the reaction is complete (Lin et al. 1985; Cheng and Abelson 1987). The stalled complexes generated with $60 \mu \mathrm{M}$ ATP are functional as ascertained by chase experiments (described in the next section; (figure 5, B \& C). Significant depletion of A2-1 complex and depletion of B complex occurred on incubation of these arrested complexes with immobilized anti-Prp21 antiserum (figure $4 \mathrm{~B}$, lane 3 ). This did not occur when reactions were incubated with preimmune-serum-bound Protein-A-Sepharose beads (figure 4B, lane 2). In immunodepletion experiments with complexes from standard splicing reactions, both $\mathrm{B}$ and A complexes were depleted, the depletion of $B$ being more complete in this instance (data not shown). Our data show that Prp21 is a component of the A2-1 complex, which contains all the five spliceosomal $U$ snRNPs. In reactions with limiting ATP, substrate RNA in the immunoprecipitated complexes was, as expected, premRNA (figure 4C, lane 3). Similar experiments to test depletion of splicing complexes by anti-Prp24 antiserum were also performed. Significant depletion of splicing complexes was not observed from reactions with limiting ATP or from standard reactions (figure $4 \mathrm{~B}$, lanes 4 and 5), which suggests either that $\operatorname{Prp} 24$ is not present in these spliceop somal complexes or that its epitopes are largely unavailable. However, the RNA species in the complexes bound to anti$\operatorname{Prp} 24$ were analysed, and we detected some pre-mRNA (figure $4 C$, lane 5). Since our binding and wash conditions were stringent, Protein-A-Sepharose beads did not retain any complexes (figure $4 \mathrm{~B}$ lane 2 and figure $4 \mathrm{C}$ lane 2 ). The precipitation of pre-mRNA by anti-Prp24 possibly reflects presence of $\operatorname{Prp} 24$ in nonspecific complexes. Thus if Prp24 is a component of complex B or A2-1 it is largely inaccessible.

\section{Prp21 is not required after A2-1 formation but may be required for $B$ to A2-1 transition}

Understanding the requirement of Prp21 beyond prespliceosome assembly could clarify if $\operatorname{Prp} 21$ and Prp24 interaction is functional. After inactivating $\operatorname{Prp} 21 \mathrm{~m} 2$ protein at different steps during assembly, we examined its requirement (figure 5A). Inactivation, prior to addition of substrate, abolished prespliceosome formation (figure $5 B$, lane 2). Further, we selectively accumulated Prp21-2-containing $B$ and A2-1 complexes and used these complexes to discern if Prp21 functions beyond complex B formation. The accumulated complexes were functional since, upon supplementing with ATP, they were chased to active spliceosomal complexes (figure $5 \mathrm{~B}$, lane 5 ). We also determined that stalled Prp21-2-containing A2-1 complex was heat stable (figure 5B, lane 4). Heat-treated Prp21-2-containing A2-1 complex, when supplemented with additional ATP and further incubated for $30 \mathrm{~min}$, converted to active spliceosomal complex A (figure 5B, lane 6). These data are corroborated by the detection of mRNA (figure 5C, lane 6). Thus, though Prp21 is present in A2-1 it is not required for conversion of A2-1 to active spliceosomes. The amount of mRNA formed after heat treatment of Prp21-2-containing A2-1 complexes was lower than that obtained upon chasing A2-1 complexes in control reactions (figure $5 \mathrm{C}$, compare lanes 5 and 6 ). This is possibly because after heat inactivation only preformed A2-1 complexes are chased, in 
A

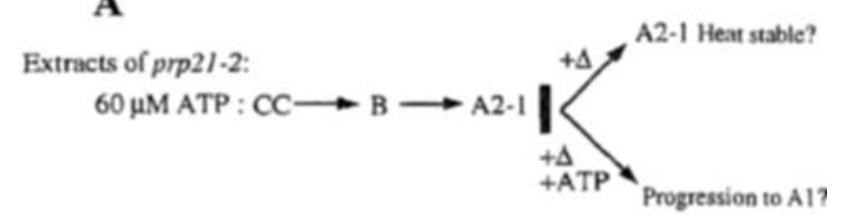

B

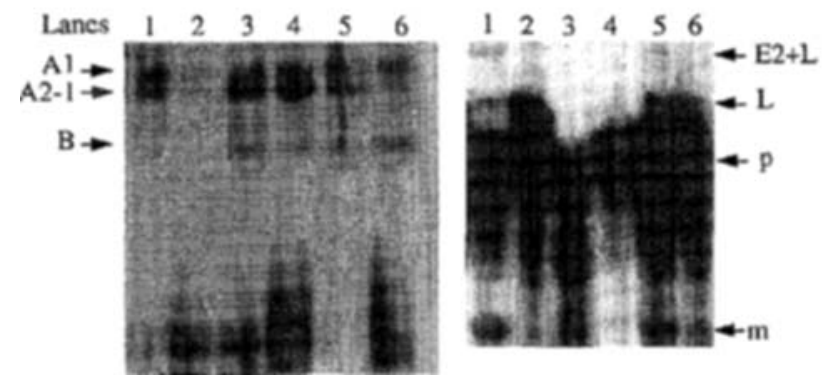

Figure 5. Functional requirement of prp21-2. Panel A shows complexes in reactions with $60 \mathrm{M}$ ATP and the scheme for testing Prp21-2 function after A2-1. Prp21-2-containing B and A2-1 complexes were subjected to heat treatment, and tested for heat stability and for reaction progression after supplementing with ATP to $3 \mathrm{mM}$. The complexes in these and control reactions were analysed on native PAGE (panel B). The substrate RNA species were resolved on denaturing PAGE (panel $\mathrm{C}: \mathrm{E} 2+\mathrm{L}$, lariat intermediate; L, lariat intron; $p$, pre-mRNA; $m, m R N A$ ). Standard reactions with $3 \mathrm{mM}$ ATP and prp2l-2 extracts prior to (lane 1) or after (lane 2) heat treatment provided controls. Stalled B and A2-1 complexes containing Prp21-2 are shown in lane 3 . In lane 5, the stalled complexes were supplemented with ATP and further incubated for $30 \mathrm{~min}$ at $23^{\circ} \mathrm{C}$. Shown in lane 4 are stalled complexes that were heat-treated at $39^{\circ} \mathrm{C}$ for $7 \mathrm{~min}$. In lane 6 heattreated complexes were supplemented with ATP and incubated at $23^{\circ} \mathrm{C}$ for $30 \mathrm{~min}$.

contrast to reactions where $\operatorname{Prp} 21$ is active and new splicing reactions can be initiated. In these chase experiments we observed that while A2-1 was converted to mature complexes, a significant amount of prespliceosomal complex B remained (figure 5B, lane 6). This was intriguing since under these conditions of heat treatment free Prp21-2 protein is inactivated and no formation of complex $B$ occurs. The $B$ complex that was observed could be due to disintegration of A2-1 complex or due to inability of B complexes to convert to A2-1. The heat-stable nature of A21 has been verified, and no increase in $B$ complex occurred in these reactions (figure 5B, lane 4). If Prp21 in A2-1 complexes is not inactivated, this fraction of Prp21 might subsequently support formation of new $B$ complexes. To test this possibility, we assembled Prp21-2-containing A2-1 complex with unlabelled actin pre-mRNA as substrate, and then heat-treated the complex. Radiolabelled actin premRNA (in excess of the first substrate) was then added as a second substrate to these heat-treated complexes, together with ATP to $3 \mathrm{mM}$. The reactions were then continued for $30 \mathrm{~min}$. Under these conditions formation of spliceosomal complexes on the second, radiolabelled substrate did not take place, nor were products of the reaction observed,
A

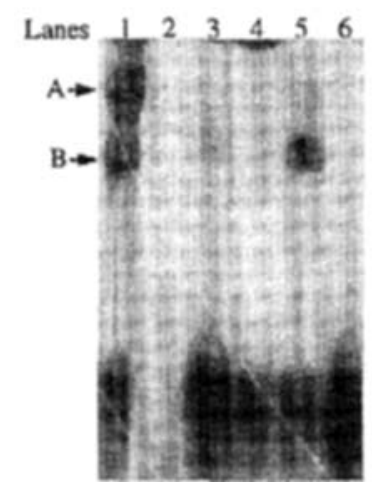

B

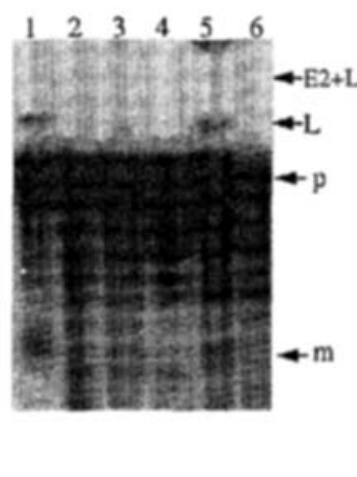

Figure 6. Inactivation of $\operatorname{Prp} 21-2$ is complete after assembly in A2-1 complex. Standard reactions with radiolabelled substrate and prp2I-2 extracts prior to (lane 1) or after (lane 2) heat treatment were done as controls. Stalled Prp21-2-containing complexes were formed with unlabelled substrate and used as follows. ATP and a second, radiolabelled substrate were added to one aliquot and the reaction stored on ice (lane 3 ) or incubated for $30 \mathrm{~min}$ at $23^{\circ} \mathrm{C}$ (lane 5). Another aliquot was heat-treated at $39^{\circ} \mathrm{C}$ for 7 min, then supplemented with ATP and the labelled substrate. These reactions were either stored on ice (lane 4) or incubated at $23^{\circ} \mathrm{C}$ for $30 \mathrm{~min}$ (lane 6). (A) The spliceosomal complexes formed on the radiolabelled substrate were visualized by autoradiography after resolution on native PAGE; $A$ denotes spliceosomes $A 2-1, A 1$ and A2-2. (B) The radiolabelled RNA reaction products were analysed by denaturing PAGE.

when the unlabelled preassembled complex was heattreated (figure $6, \mathrm{~A} \& \mathrm{~B}$, lane 6). The second substrate was spliced only when the preassembled Prp21-2-containing A2-1 was not heat-treated (figure $6, \mathrm{~A} \& \mathrm{~B}$, lane 5). Thus heat treatment even after A2-1 assembly inactivates Prp21-2 and does not support new B complex formation. Thus complex B seen in reactions where Prp21-2-containing A2-1 complexes were heat-treated (figure 5B, lane 6) possibly reflects failure of $B$ to $A 2-1$ conversion, suggesting Prp21 requirement at this step.

\section{Kinetics of complex formation in revertant extracts suggest a role for Prp21 in $B$ to A2-1 transition}

While in the revertant strain prp24-1 prp21-2 there is complete suppression of prp21-2 and prp24-1, we investigated whether the kinetics of in vitro assembly differ between wildtype and revertant extracts. For these comparisons, reactions were done with wild-type or revertant extracts and the relative abundance of $\mathrm{B}$ and $\mathrm{A}$ complexes (A2-1, $\mathrm{A} 1$ and $\mathrm{A} 2$ 2) determined by densitometric scanning of the electrophoresis gels. In control reactions with untreated wild-type extract, complex $\mathrm{B}$ was formed within $2 \mathrm{~min}$ at $23^{\circ} \mathrm{C}$ (figure $7 \mathrm{~A}$, lane $1 ; \mathrm{B}$ complex $88.6 \%$ and $\mathrm{A}$ complex $10.8 \%$ ), and by $4 \mathrm{~min}$ at $23^{\circ} \mathrm{C}$ there was almost equal distribution between $\mathrm{B}$ and the $\mathrm{A}$ complexes (figure 7A, lane 2; B complex $53.0 \%$ and $A$ complex $45.8 \%$ ). There was no difference in kinetics when wild-type extracts were heat-treated prior to the reactions (figure 7A, compare lanes 2 and 6 ; in lane $6 \mathrm{~B}$ complex 
A
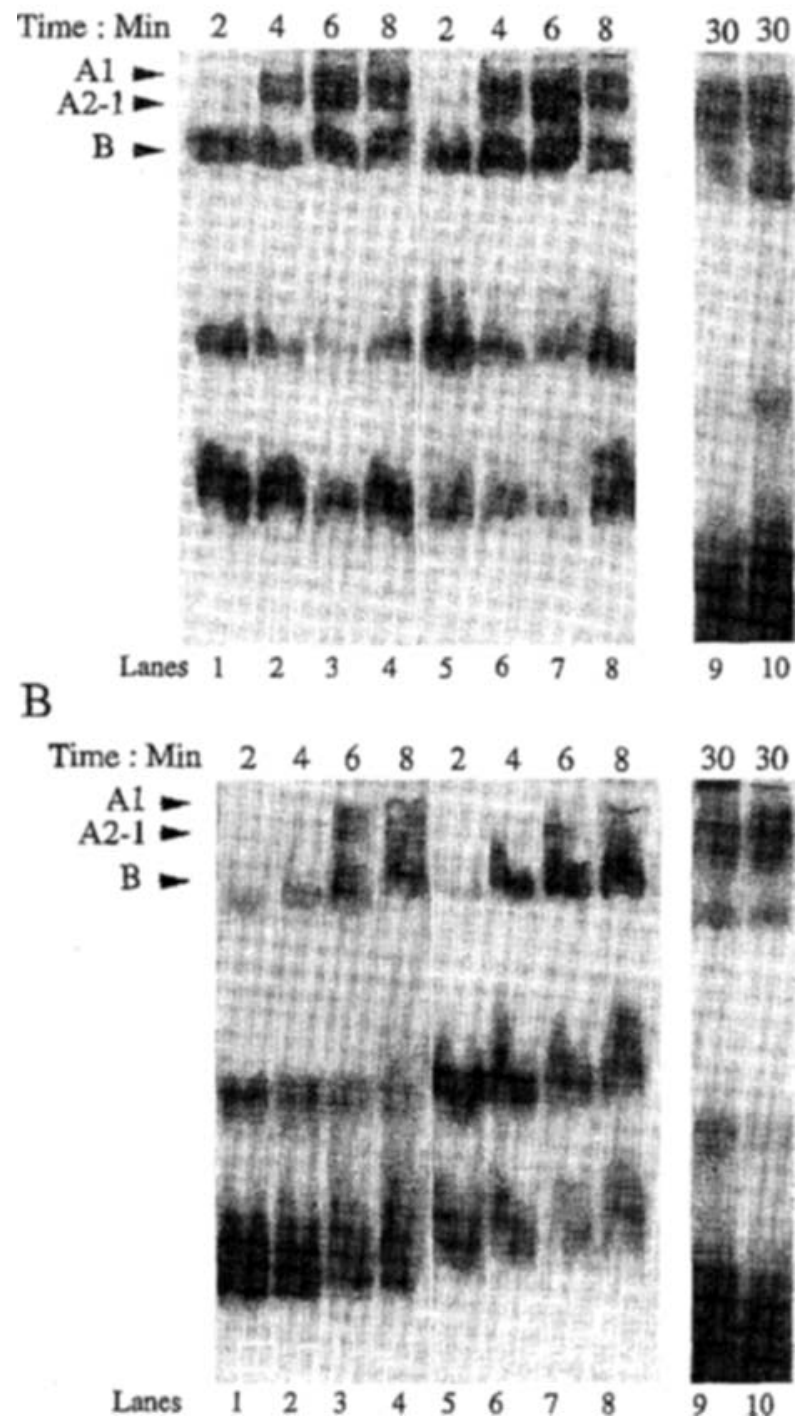

Figure 7. Kinetic analysis of early spliceosome assembly events. Extracts from wild-type cells, panel A, and revertant cells, panel B, were used in standard reactions either prior to (lanes 1 to 4 and lane 9) or after (lanes 5 to 8 and lane 10) heat treatment. The kinetics of assembly were assessed on native PAGE gels. The time points $(2,4,6,8$ or $30 \mathrm{~min})$ at which the reactions were stopped are indicated above each lane.

$50.8 \%$ and $A$ complex $47.8 \%$ ). Revertant extracts behaved similarly when they were not heat-treated (figure $7 \mathrm{~B}$, lanes 1 to 4 ). B complex was formed by $2 \mathrm{~min}$ (B complex $81.0 \%$ A complex $16.8 \%$ ) and by $6 \mathrm{~min}$ there was an almost equal distribution between $B$ and $A$ complexes (58.4\% and $41.2 \%$ respectively). There is thus only a small delay in conversion of B to A complexes in revertant extracts. However, when revertant extracts were heat-treated prior to the reaction, there was a significant delay in the conversion of $\mathbf{B}$ complexes to active spliceosomal complexes (figure $7 \mathrm{~B}$, lanes 5 to 8 ). At 6 min B complexes predominated (B complex $81.0 \%$ and $A$ complex $19.1 \%$ ) and this pattern continued even up to $8 \mathrm{~min}$
(B complex $70.5 \%$ and A complex 27\%). Slow progression of $\mathrm{B}$ to A complexes is clearly only a kinetic effect, because at a later time point there were no differences between the wild-type and revertant extracts (figure $7 \mathrm{~A}$ lane 10 and figure 7B lane 10). In vitro heat inactivation of prp24-1 extract does not block assembly of B and A2-1, but there is no progression beyond A2-1. The arrested complexes can be chased by the addition of recombinant Prp24 (A. Ghetti and J. Abelson, personal communication). These observations, together with our analysis of prp21-2 prp24-1 extracts, suggest a requirement for Prp21-2 in B to A2-1 conversion. These data have a significant implication for suppression in prp21-2 prp24-1, since this is the step at which U4/U5/U6 tri-snRNP joins the assembly pathway.

\section{Discussion}

Distinct mutations in prp24-1 are suppressed by a mutation in a nonconserved domain of PRP21 through indirect interaction

Prp24, a U6-snRNP-binding protein, has three conserved RNA recognition motifs (RRMs), which are defined in several core snRNP and splicing proteins (Shannon and Guthrie 1991; Birney et al. 1993; Tang et al. 1996). The phenotypes of prp 24- $l$ are possibly due to two mutations: one, lysine 191 to glutamic acid in RRM2, the other a conservative lysine 46 to arginine in ribonucleoprotein (RNP) submotif of RRM1. Mutations in other alleles of prp24 isolated as suppressors of mutant U4 snRNA cluster to RNP submotifs of a different domain, RRM3 (Shannon and Guthrie 1991). The RNP submotifs in RRMs contain residues that contact RNA; thus the reduced U6 binding observed in prp24-1 and prp24-2 is explained (Shannon and Guthrie 1991; Vaidya et al. 1996). In human U1 A and U2 B" proteins specificity of interaction with RNA and with other proteins was altered by even conservative amino-acid substitutions (Scherly et al. 1990). Since prp21-2 is a dominant suppressor of only prp24-1, we possibly have uncovered different functional domains in Prp24. A systematic analysis of the two mutations in prp241 could delineate Prp24 domains that participate in RNA interactions versus those that participate in protein interactions. Prp21, its human homologue SF3a 120, and the worm homologue CePrp21 contain the conserved SURP module first identified in suppressor-of-white-apricot and prp21/spp91, and have sequence similarity outside of this module (Spikes et al. 1994; Kramer et al. 1995). The missense mutation in prp21-2 and spp91-1 are closely positioned. Both these mutations result in amino-acid substitutions in residues close to the two deduced SURP modules in Prp21 (Chapon and Legrain 1992; and these studies). The proximity of these two mutations, and their location in a region of sequence similarity together point to functional importance of the non-SURP domain in spliceosomal protein-protein interactions of Prp21.

As mentioned before suppression of prp 24-1 by prp21-2 suggested physical interaction of the proteins with 
functional suppression, or a functional interaction with no direct physical contact between the proteins. Results of the two-hybrid assay suggest that physical interaction between wild-type or mutant Prp21 and Prp24 proteins does not occur, thereby implying indirect interaction. However, certain considerations cannot be forgone. Firstly, interaction may require prior assembly of Prp9.Prp11.Prp21 ternary complex. Secondly, the lack of interaction among fusion proteins may be because of steric hindrance by the Gal4 domains, or due to their altered conformations. Other instances where genetic interactions do not replicate as direct contacts in the two-hybrid assay are known. Mud2, the yeast U2AF65 homologue, and Msl1, the yeast $\mathrm{U}_{2} \mathrm{~B}^{\prime \prime}$ homologue, display synthetic-lethal interactions yet do not seem to interact by the two-hybrid assay (Tang et al. 1996).

\section{In vitro suppression between prp21-2 and prp24-1}

In vitro heat treatment that inactivates either Prp21-2 or Prp24-1 does not affect revertant extracts. Complementation of inactivated Prp21-2 required the simultaneous addition of purified Prp9, Prp11 and Prp21 proteins-all of which form a ternary complex (Wiest et al. 1996; and our unpublished observations). Thus an inactive ternary complex results from inactivation of any one protein. Complementation does not require Prp24, therefore association of wild-type Prp24 with the inactive Prp9.Prp11.Prp21 ternary complex is unlikely. Furthermore, as mentioned previously, in vitro heat inactivation of prp24-1 extracts does not affect $B$ complex formation and these inactive extracts are rescued by the addition of $\operatorname{Pr} 24$ protein alone (A. Ghetti and J. Abelson, personal communication). These data imply absence of direct interaction between Prp21 and Prp24, prior to the formation of the Prp9.Prp11.Prp21 complex, and corroborate the results of our two-hybrid assay.

\section{Immunoprecipitation of $s$ RNAs with anti-Prp24 and anti-Prp 21 antisera does not indicate stable association between these proteins}

We examined if the dominant suppression of prp24-1 by prp21-2 manifests in Prp21-2 protein associating with U4/ U6 snRNAs. Extracts from prp24-1 prp21-2 demonstrate mutual restoration of the association of each protein with the appropriate snRNA. However, coprecipitation of $\mathrm{U} 2$ and U6 snRNAs by anti-Prp24 or anti-Prp21 antiserum was not observed as one may expect for stable yet indirect interactions. Possibly, interaction in the spliceosome is not revealed in the profiles of precipitated snRNA owing to weak or transient contacts. U1 snRNA precipitation by antiPrp21 antiserum occurred even with inactive Prp21 protein, and at fairly stringent salt conditions. The likely reason is that it reflects an association of Prp21 with the commitment complex, similar to that observed for Prp11 (Ruby et al. 1993).
Interaction between prp21-2 and prp24-1 occurs during conversion of prespliceosome complex $B$ to the intermediate A2-1 complex

By immunodepletion of splicing complexes we have demonstrated that Prp21 is a component of A2-1 complex, which is known to contain U1 snRNP, U2 snRNP and the U4/U5/U6 tri-snRNP. Although we did not observe precipitation of U6 snRNA with anti-Prp21 antiserum, Prp21 has been detected in U6-containing complexes by use of a sensitive assay (Wiest $e t$ al. 1996). U6 immunoprecipitation in this latter study may be due to U2/U6 base-pairing in the spliceosome or because of interaction mediated by a U6-snRNA-associated factor. A role for Prp24 in this association, while an attractive postulate, is not confirmed here since our immunodepletion experiments do not unambiguously demonstrate Prp24 in splicing complexes. Obvious yet speculative interpretations for nonquantitative precipitation of $B$ and A2-1 complexes by anti-Prp24 are partial inaccessibility of Prp24 or precipitation of an undetectable minor complex. Salt-sensitive and nonquantitative immunoprecipitation of RNA-protein complexes are known (Tang et al. 1996). We note that while direct evidence does not exist, there are data suggesting a function for $\mathrm{Prp} 24$ in stabilizing U6 snRNA in the spliceosome upon exit of U4 snRNA (Fortner et al. 1994; Brow and Vidaver 1995; Ghetti et al. 1995). Our genetic data and these reports suggest that Prp24 may be a component of spliceosomes where an interaction between Prp21 and Prp24 can occur. A likely step is the A2-1 intermediate complex, and one way to ascertain this could be through specific immunoprecipitation of labelled U2 snRNA with anti-Prp24 antiserum.

We report here that Prp21, though present in the A2-1 complex, may not be required for A2-1 to A1 conversion. Our data suggest its requirement during formation of A2-1 from complex $B$. Thus a relevant point of suppression in prp21-2 prp24-1 could be during transition of complex B to A2-1. Kinetic analysis of assembly in heat-treated extracts from prp21-2 prp24-1 strain strongly support this idea. Suppression of the inability to form prespliceosomes with inactive Prp21-2 is observed in these extracts. Since prespliceosome assembly is not primarily rate-liniting, an explicit reason for this suppression is not obvious. Interaction between the two proteins during spliceosome disassembly and recycling has not been addressed and could occur. Prp24 has recently been shown to promote the reannealing of $U 4$ and U6 snRNPs and thus plays a role in recycling spliceosomal components (Raghunathan and Guthrie 1998). Predictions are that Prp21 remains in complexes more mature than the A1 complex, possibly even in disassembling complexes. The presence of Prp21-2 and Prp24-1 in the same mature or disassembling particle may account for suppression of the prp 24-1 phenotype. The suppression at the early stages of spliceosomal assembly could then be a manifestation of their prior interaction which maintains the proteins in a conformation to fulfil their later roles. Thus our genetic, in vivo and in vitro analyses of suppression between prp21-2 and prp24- 1 identify an association between a U2-snRNAassociated protein and a U6-snRNA-associated protein. 


\section{Acknowledgements}

We are indebted to Prof. J. Abelson, Caltech, USA, for support during standardization of some experiments in his laboratory. We also gratefully acknowledge unpublished data, plasmids $P R P 21 \mathrm{pBS}$ and PRP24pBS, and anti-Prp21 and anti-Prp24 antisera provided by his laboratory. We particularly thank Dr D. Wiest and Dr A. Ghetti for their insightful suggestions. We are grateful to our colleagues S. Vasudevan, Gopal Battu and S. Sinha Ray for inputs; and Dr K. Muniyappa for his comments and for facilitating densitometric scanning. V. V. received a CRC, UK, travel fellowship, and U. V. is recipient of grants from the Department of Biotechnology and the Council of Scientific and Industrial Research of the Government of India.

\section{References}

Arenas J. and Abelson J. 1993 The Saccharomyces cerevisiae $P R P 2 I$ gene product is an integral component of the prespliceosome. Proc. Natl. Acad. Sci. USA 90, 6771-6775.

Beggs J. D. 1993 Yeast protein factors involved in pre-mRNA splicing. Mol. Biol. Rep. 18, 99-103.

Birney E., Kumar S. and Krainer A. R. 1993 Analysis of the RNArecognition motif and RS and RGG domains: conservation in metazoan pre-mRNA splicing factors. Nucl. Acids Res. 21, 5803-5816.

Brow D. A. and Guthrie C. 1988 Spliceosomal RNA U6 is remarkably conserved from yeast to mammals. Nature 334, 213-218.

Brow D. A. and Vidaver R. M. 1995 An element in human U6 snRNA destabilizes the U4/U6 spliceosomal RNA complex. RNA 1, 122-131.

Chapon C. and Legrain P. 1992 A novel gene, spp91-1, suppresses the splicing defect and pre-mRNA nuclear export in the prp9-1 mutant. EMBO J. 11, 3279-3288.

Cheng S. C. and Abelson J. 1987 Spliceosome assembly in yeast. Genes Dev. 1, 1014-1027.

Chien C. T., Bartel P. L., Sternglanz R. and Fields S. 1991 The two hybrid system: A method to identify and clone genes for proteins that interact with a protein of interest. Proc. Natl. Acad. Sci. USA 88, 9578-9582.

Fields S. and Song O. K. 1989 A novel genetic system to detect protein-protein interactions. Nature 340, 245-246.

Fortner D. M., Troy R. G. and Brow D. A. 1994 A stem loop in U6 RNA defines a conformational switch required for pre-mRNA splicing. Genes Dev. 8, 221-233.

Ghetti A., Company M. and Abelson J. 1995 Specificity of Prp24 binding to RNA: A role for Prp24 in the dynamic interaction of U4 and U6 snRNAs. RNA 1, 132-145.

Gozani O., Patton J. G. and Reed R. 1994 A novel set of spliceosome associated proteins and the essential splicing factor PSF bind stably to the pre-mRNA prior to the catalytic step II of the splicing reaction. EMBO J. 11, 3356-3367.

Guthrie C. 1991 Messenger RNA splicing in yeast: clues as to why the spliceosome is a ribonucleoprotein. Science 253, 157-163.

Jandrositz A. and Guthrie C. 1995 Evidence for a Prp24 binding site in U6 snRNA and in a putative intermediate in the annealing of U6 and U4 snRNAs. EMBO J. 14, 820-832.

Kim S. H. and Lin R. J. 1996 Spliceosome activation by PRP2 ATPase prior to the first transesterification reaction of premRNA splicing. Mol. Cell. Biol. 16, 6810-6819.
Kramer A., Mulhauser K., Wersig K., Groning K., Brosi R. and Bilbe G. 1995 Mammalian splicing factor SF3a 120 represents a new member of the SURP family of proteins and is homologous to the essential splicing factor PRP21p of S. cerevisiae. RNA 1, 260-272.

Legrain P., Chapon C. and Gallison F. 1993 Interaction between PRP9 and SPP91 splicing factors identify a protein complex required in pre-spliceosome assembly. Genes Dev, 7, 1390-1399.

Lin R. J., Newman A. J., Cheng S. C. and Abelson J. 1985 Yeast mRNA splicing in vitro. J. Biol. Chem. 260, 14780-14792.

Madhani H. D. and Guthrie C. 1994 Dynamic RNA-RNA interactions in the spliceosome. Annu. Rev. Genet. 28, 1-26.

Moore M. J., Query C. C. and Sharp P. A. 1993 Splicing of precursors to mRNA by the spliceosome. In The RNA world (ed. R. Gesteland and J. Atkins), pp. 303-357. Cold Spring Harbor Laboratory Press, Cold Spring Harbor.

Raghunathan P. and Guthrie C. 1998 A spliceosomal recycling factor that reanneals $\mathrm{U} 4$ and $\mathrm{U} 6$ small nuclear ribonucleoprotein particles. Science 279, 857-860.

Ruby S. W. and Abelson J. 1991 Pre-mRNA splicing in yeast. Trends Genet. 7, 79-85.

Ruby S. W., Chang T. H. and Abelson J. 1993 Four yeast spliceosomal proteins (PRP5, PRP9, PRP11 and PRP21) interact to promote U2 snRNP binding to the pre-mRNA. Genes Dev. 7, 1909-1925.

Scherly D., Boelens W., Van Vernooij W. J., Dathan N. A., Hamm I. and Mattaj I. 1990 Major determinants of the specificity of interaction between small nuclear ribonucleoprotein U1A and U2B" and their cognate RNAs. Nature 345, 502-506.

Seshadri V. and Vijayraghavan U. $1995 \mathrm{~A}$ method for rapid mapping of mutations by plasmid rescue strategy in Saccharomyces cerevisiae. J. Genet. 74, 127-138.

Shannon K. W. and Guthrie C. 1991 Suppressors of U4 snRNA mutations define a novel U6 snRNP protein with RNA binding motifs. Genes Dev. 5, 773-785.

Spikes D. A., Kramer J., Bingham P. M. and van Doren K. 1994 SWAP pre-mRNA splicing regulators are a novel, ancient protein family sharing a highly conserved sequence motif with the prp21 family of constitutive splicing proteins. Nucl. Acids Res. 22, 4510-4519.

Tang J., Abovich N. and Rosbash M. 1996 Identification and characterization of a yeast gene encoding the U2 small nuclear ribonucleoprotein particle B" protein. Mol. Cell. Biol. 16, 2787-2795.

Vaidya V. C, Seshadri V. and Vijayraghavan U. 1996 An extragenic suppressor of prp24-1 defines genetic interaction between PRP24 and PRP21 gene products of Saccharomyces cerevisiae. Mol. Gen. Genet. 250, 267-276.

Vijayraghavan U. and Abelson J. 1989 Pre-mRNA splicing in yeast. In Nucleic acids and molecular biology (ed. F. Eckstein and D. M. J. Lilley), vol. 3, pp. 197-215. Springer, Berlin.

Vijayraghavan U., Company M. and Abelson J. 1989 Isolation and characterization of pre-mRNA splicing mutants of $S$. cerevisiae. Genes Dev. 3, 1206-1216.

Wiest D. K., O'Day C. L. and Abelson J. 1996 In vitro studies of the Prp9.Prp11.Prp21 complex indicate a pathway for U2 small nuclear ribonucleoprotein activation. J. Biol. Chem. 271, 33268-33276.

Xu D., Nouraini S., Field D., Tang S. J. and Friesen J. D. 1996 An RNA-dependent ATPase associated with U2/U6 snRNAs in premRNA splicing. Nature 381, 709-713.

Yean S. L. and Lin R. J. 1991 U4 small nuclear RNA dissociates from the spliceosome and does not participate in the subsequent splicing reaction. Mol. Cell. Biol. 11, 5571-5577. 